\title{
Recurrent Thrombosis in Patients with Antiphospholipid Syndrome Receiving Newer Oral Anticoagulants: A Case Report and Review of Literature
}

\author{
Akanksha Joshi, MD; Jason Hong, MD; and Chokkalingam Siva, MD, MS, FACP
}

\begin{abstract}
We present the case of a patient with primary APS who had a recurrence of thrombotic event while on treatment with rivaroxaban and had to be restarted on warfarin. The current literature on recurrence of thrombotic events in patients with antiphospholipid syndrome (APS) treated with newer oral anticoagulants (NOAC) is also reviewed. Relevant case reports and case series were identified by searching the Medline database using the key words antiphospholipid syndrome, anticoagulants and names of the NOACs, and data on individual patients was abstracted. We identified several reports on the failure of newer anticoagulants in APS, as well as cases and clinical trial results reporting efficacy. We conclude that treatment strategies for APS should be tailored cautiously when using NOACs.
\end{abstract}

Keywords: Anti-ß2-glycoprotein antibodies; Anti-cardiolipin antibodies; Anticoagulants; Anti-phospholipid Syndrome; Newer oral anticoagulant; Rivaroxaban; Warfarin

A ntiphospholipid antibody syndrome (APS) is characterized by venous or arterial thrombosis and/or pregnancy morbidity with positivity of one of three serologies: (1) lupus anticoagulant, (2) anti-cardiolipin antibodies, or (3) anti- $\beta 2$ glycoprotein 1 antibodies. Conventionally, APS has been treated with warfarin with the goal international normalized ratio (INR) between 2 and 3 . The hope for alternative therapeutic options has risen recently with the advent of new oral anti-coagulants (NOACs). However, there have been several reports in the literature about patients with APS developing recurrent thrombosis while being treated with the NOACs. We present a patient with primary APS who had a recurrence of thrombotic event while on treatment with rivaroxaban and had to be restarted on warfarin. We reviewed the literature to identify similar cases that had recurrent thrombosis while on NOACs and summarized them with details of duration of NOAC therapy and types of recurrent thromboembolic events in an attempt to recognize the possible causes and to identify APS patients at risk for failure (Table 1). ${ }^{1-11}$

\section{Case Presentation}

A woman, aged 54 years, with history of APS, recurrent deep venous thrombosis (DVT), status post inferior vena cava
(IVC) filter placement, adrenal hemorrhage, and chronic kidney disease (CKD) was admitted to the hospital for progressively worsening shortness of breath for several weeks. She had been switched from warfarin to rivaroxaban $20 \mathrm{mg}$ daily a year before. Physical examination was remarkable for nasal septal perforation, low oxygen saturations, and fine bi-basilar inspiratory crackles. Laboratory tests were significant for thrombocytopenia (platelet count 61), mild leukocytosis $\left(12 \times 10^{9}\right)$, microcytic anemia (hemoglobin 8 , mean corpuscular volume 73.6), and renal impairment (glomerular filtration rate 24) at baseline. Prothrombin time was noted to be prolonged at 16.4 seconds, but rivaroxaban specific anti-factor Xa assay was not done. Lupus anticoagulant was negative but the other APS serologies were significantly elevated as shown in Table 2.

Ventilation perfusion scan, electrocardiogram, and cardiac enzymes were negative. Bronchoscopic lavage was suggestive of diffuse alveolar hemorrhage, with hemosiderin laden macrophages on iron stain, but no signs of pulmonary hemorrhage were seen either during bronchoscopy or in the computed tomography of chest. Transthoracic echocardiogram and a confirmatory transesophageal echocardiogram demonstrated a right atrial thrombus (Figures 1 and 2) without
Corresponding Author: Akanksha Joshi, MD, Division of Rheumatology, University of Missouri School of Medicine,5 Hospital Drive, Columbia, MO 65212 Tel: (573) 882-8095, Fax: (573) 882-I380, Email: akankshadr@gmail.com
Received: November 3, 2016

Revised: March 21, 2017

Accepted: June 19, 2017

doi: $10.3121 / \mathrm{cmr} .2017 .1349$ 
Table 1. Failure of newer anticoagulants to prevent thrombotic events in antiphospholipid syndrome.

\begin{tabular}{|c|c|c|c|c|c|}
\hline & Patients & & & & Duration of \\
\hline Case Series & (N) & Age & Gender & Type of Thrombotic Event & Treatment \\
\hline \multirow{2}{*}{$\begin{array}{l}\text { Son et al. }{ }^{1} \\
\text { (2015, Poland) }\end{array}$} & \multirow[t]{2}{*}{2} & 36 & $\mathrm{~F}$ & DVT & $5 \mathrm{~m}$ \\
\hline & & 56 & $\mathrm{~F}$ & DVT & $2 \mathrm{~m}$ \\
\hline \multirow{3}{*}{$\begin{array}{l}\text { Win et al. }{ }^{2} \\
(2014, \text { US })\end{array}$} & \multirow[t]{3}{*}{3} & 46 & M & DVT & $6 \mathrm{~m}$ \\
\hline & & 19 & $\mathrm{~F}$ & Venous thrombosis & $?$ \\
\hline & & 53 & $\mathrm{~F}$ & TIA, Neurologic symptoms & $12 \mathrm{~m}$ \\
\hline \multirow{3}{*}{$\begin{array}{l}\text { Schaefer et. al. }{ }^{3} \\
(2014, \text { USA) }\end{array}$} & \multirow[t]{3}{*}{3} & 43 & $\mathrm{~F}$ & Cerebral emboli & $5 \mathrm{~m}$ \\
\hline & & 59 & $\mathrm{~F}$ & Cortical infarcts & $6 \mathrm{~m}$ \\
\hline & & 32 & M & Portal vein thrombosis & $6 \mathrm{~m}$ \\
\hline \multirow{8}{*}{$\begin{array}{l}\text { Signorelli et al. }{ }^{4} \\
(2016, \text { USA) }\end{array}$} & \multirow[t]{8}{*}{8} & 18 & $\mathrm{~F}$ & Neurologic symptoms & $1 \mathrm{w}$ \\
\hline & & 42 & M & DVT & $3 \mathrm{~m}$ \\
\hline & & 30 & $\mathrm{~F}$ & DVT & $2 \mathrm{~m}$ \\
\hline & & 38 & M & Arterial thrombosis & $3 \mathrm{~m}$ \\
\hline & & 29 & M & Refractory HA & weeks \\
\hline & & 34 & $\mathrm{~F}$ & MI & $3 \mathrm{~m}$ \\
\hline & & 52 & $\mathrm{~F}$ & Cerebral Infarct & $3 \mathrm{~m}$ \\
\hline & & 46 & $\mathrm{~F}$ & Stroke & $12 \mathrm{~m}$ \\
\hline $\begin{array}{l}\text { Vergallo et al. }^{5} \\
(2016, \text { USA) }\end{array}$ & 1 & 23 & M & NSTEMI & $18 \mathrm{~m}$ \\
\hline $\begin{array}{l}\text { Noel et al. }{ }^{6} \\
\text { (2015, France) }\end{array}$ & 1 & 18 & M & Microthombotic event & $8 \mathrm{~m}$ \\
\hline $\begin{array}{l}\text { Haladyj et al. }{ }^{7} \\
\text { (2016, Poland) }\end{array}$ & 1 & NR & NR & Pulmonary emolism & $20 \mathrm{~m}$ \\
\hline $\begin{array}{l}\text { Joalland et al. }^{8} \\
\text { (2014, France) }\end{array}$ & 1 & 17 & M & Venous thrombosis & NR \\
\hline $\begin{array}{l}\text { Delgado et al. }{ }^{9} \\
\text { (2015, Spain) }\end{array}$ & 1 & 77 & $\mathrm{~F}$ & Stroke & $2 \mathrm{~m}$ \\
\hline $\begin{array}{l}\text { Rokos et al. }{ }^{10} \\
\text { (2016, Osterreich) }\end{array}$ & 1 & 46 & $\mathrm{~F}$ & Stroke & $6 \mathrm{w}$ \\
\hline Malec et al. ${ }^{11}$ & 6 & 62 & $\mathrm{~F}$ & NR & $20 \mathrm{~m}$ \\
\hline (2016, Poland) & & 47 & $\mathrm{~F}$ & NR & $18 \mathrm{~m}$ \\
\hline & & 62 & M & NR & $17 \mathrm{~m}$ \\
\hline & & 43 & M & NR & $43 \mathrm{~m}$ \\
\hline & & 36 & $\mathrm{~F}$ & NR & $5 \mathrm{~m}$ \\
\hline & & 56 & $\mathrm{~F}$ & NR & $2 \mathrm{~m}$ \\
\hline
\end{tabular}

DVT, Deep vein thrombosis; TIA, Transient ischemic attack; HA, Headache; MI, Myocardial Infarction; NSTEMI, NonST elevation myocardial infarction; NR, Not reported, m, months; w, week(s). 
Table 2. Patient's APS serologies.

\begin{tabular}{lc} 
Serology & Value (n<20) \\
\hline$\beta 2$ Glycoprotein 1 Ab IgA & 195.5 \\
$\beta 2$ Glycoprotein 1 Ab IgG & $>6100$ \\
$\beta 2$ Glycoprotein 1 Ab IgM & 11.7 \\
Anti-Cardiolipin IgA & 197.3 \\
Anti-Cardiolipin IgG & $>2024$ \\
Anti-Cardiolipin IgM & 77.5 \\
\hline
\end{tabular}

any evidence of a patent foramen ovale. Patient was placed on heparin drip and started on warfarin bridge. Follow-up cardiac magnetic resonance imaging showed aortic arch and right atrial thrombi, which were removed surgically. Other rheumatology serological work up was negative, and it was determined that all the manifestations were attributable to APS. Patient improved after surgical intervention and was discharged on warfarin therapy with the goal INR of 2.5 to 3 .

\section{Discussion}

Unless there are specific contraindications such as allergy, intolerance, or documented poor efficacy, vitamin $\mathrm{K}$ antagonists (VKAs), such as warfarin, should be the first choice in thrombotic APS as recommended by the APS Treatment Trends Task Force during the 14th International Congress on Antiphospholipid Antibodies. ${ }^{12}$ VKAs work by inhibiting vitamin $\mathrm{K}$ dependent factors in the coagulation cascade namely Factor II, VII, IX, and X; whereas, NOACs work by inhibiting either thrombin (dabigatran) or Factor Xa (rivaroxaban, apixaban, and edoxaban). Our patient was noted to have switched from warfarin to rivaroxaban therapy and subsequently developed an atrial and aortic arch thrombosis indicating failed rivaroxaban therapy. Similarly, there are at least 28 other cases of failure of NOACs in preventing thrombotic events in APS reported in literature thus far, which have been summarized in Table 1 . Dufrost et $a^{13}$ recently published a systematic literature review of 122 APS patients

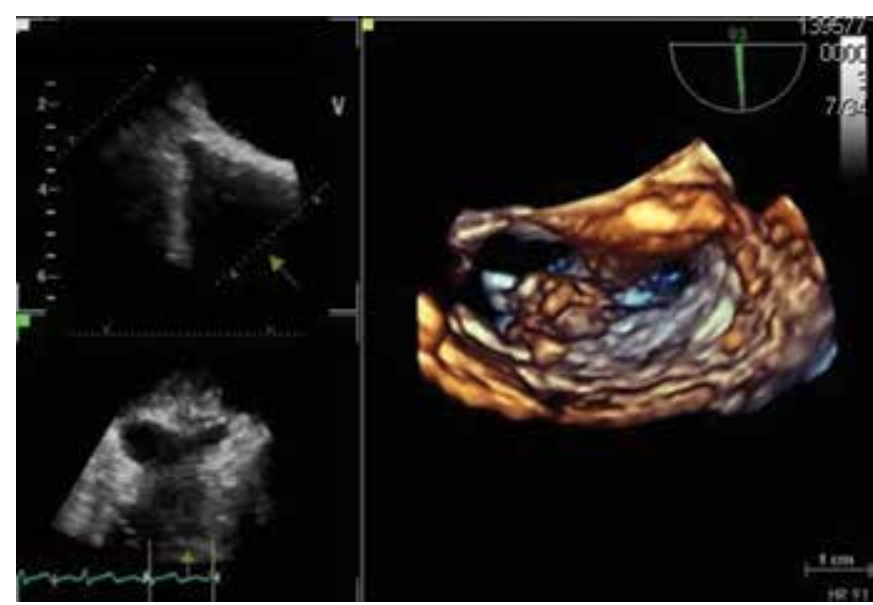

Figure 1. Transthoracic echocardiogram revealed a right atrial thrombus without evidence of a patent foramen ovale. identified in the literature to have been treated with NOACs and found that 19 of them had recurrent thrombosis while on NOACs.

The results of the RAPS trial, a randomized controlled, open label non-inferiority trial that compared rivaroxaban with warfarin to treat patients with thrombotic antiphospholipid syndrome, with or without systemic lupus erythematosus (RAPS) ${ }^{14}$ was recently published. The investigators concluded that the NOACs are non-inferior to VKAs. In this trial, the primary end point was endogenous thrombin potential (ETP), and the secondary endpoint was recurrence of thrombosis during the 210 day follow-up period. The RAPS study did not have sufficient numbers of patients in either arm to achieve enough power for definite clarification. ${ }^{13}$ The investigators reported non-inferiority of rivaroxaban as compared to VKAs, as the ETP for rivaroxaban did not reach the non-inferiority level, which was set at $<20 \%$ difference from warfarin in mean percentage change. However, the peak thrombin generation for rivaroxaban was significantly higher at 93.8 $\mathrm{nMol} / \mathrm{L}$ as compared to warfarin at $79.9 \mathrm{nMol} / \mathrm{L}$. The study also did not include enough high-risk patients as defined by triple antibody positivity, arterial thrombosis, and recurrent venous thrombosis. ${ }^{13}$

However, there have been reports of success as well. Betancur et $a{ }^{15}$ reviewed eight patients with no recurrences of thrombosis after a 19-month mean follow up. Duration of therapy ranged from 2 months to 36 months. Kunk et al ${ }^{16}$ also reviewed 10 patients with definitive APS per Sydney criteria with no recurrences of thrombosis after at least a 36-month duration of therapy. The largest case series of 35 patients was described by Sciascia et al, ${ }^{17}$ wherein the authors reported no recurrence of thrombosis during a follow-up period of 10 months after treatment with rivaroxaban.

The patient we report here had been switched from warfarin to rivaroxaban one year prior to her presentation. One could

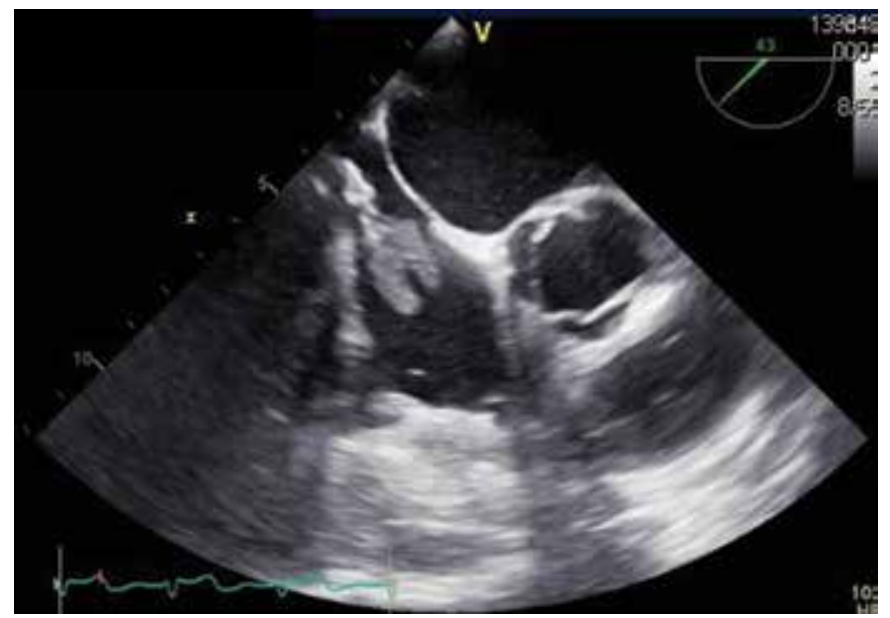

Figure 2. Transesophageal echocardiogram confirmed right atrial thrombus without evidence of a patent foramen ovale. 
make an argument for the efficacy of NOACs, since she did not have any thromboembolic events during this one year. It should also be noted that the majority of recurrent thrombotic events occurred within the first 6 months of starting treatment with NOACs. Our patient also had very high titer of two antibodies for APS. Each NOAC inhibits the coagulation pathway by inhibiting a single factor; however, VKAs work by inhibiting multiple factors in the coagulation cascade. In patients with APS who have triple antibodies positive or very high concentrations of antibodies, such as the patient we discuss, the single factor inhibition may not be effective. Our patient also had an IVC filter placed in 2008, and one could speculate possible biocompatibility problems related to the filter might also have been a contributing factor in the development of recurrent thrombosis.

\section{Conclusion}

Treatment strategies for APS should be tailored cautiously as NOACs, even if more convenient, may not always be effective substitutes for warfarin. Ongoing clinical trials to determine the safety and efficacy of NOACs in APS may lead to additional clarity. ${ }^{14,18}$ This uncertainty should be discussed with the patients who should also be involved in the decisionmaking process.

\section{References}

1. Son M, Wypasek E, Celinska-Lowenhoff M, Undas A. The use of rivaroxaban in patients with antiphospholipid syndrome: A series of 12 cases. Thromb Res 2015;135:1035-1036.

2. Win K, Rodgers GM. New oral anticoagulants may not be effective to prevent venous thromboembolism in patients with antiphospholipid syndrome. Am J Hematol 2014;89:1017.

3. Schaefer JK, McBane RD, Black DF, Williams LN, Moder KG, Wysokinski WE. Failure of dabigatran and rivaroxaban to prevent thromboembolism in antiphospholipid syndrome: a case series of three patients. Thromb Haemost 2014;112:947950.

4. Signorelli F, Nogueira F, Domingues V, Mariz HA, Levy RA. Thrombotic events in patients with antiphospholipid syndrome treated with rivaroxaban: a series of eight cases. Clin Rheumatol 2016;35:801-805.

5. Vergallo R, Aguirre AD, Abtahian F, Minami Y, Soeda T, Chatzizisis YS, Croce K, Jang IK. Recurrent myocardial infarctions and premature coronary atherosclerosis in a 23-year-old man with antiphospholipid syndrome. Thromb Haemost 2016;115:237-239.

6. Noel N, Dutasta F, Costedoat-Chalumeau N, Bienvenu B, Mariette X, Geffray L, Sene D, Chaidi RB, Michot JM, Fain O, Darnige L, Ankri A, Cacoub P, Piette JC, Saadoun D. Safety and efficacy of oral direct inhibitors of thrombin and factor Xa in antiphospholipid syndrome. Autoimmun Rev 2015; 14:680-685.

7. Haładyj E, Olesińska M. Rivaroxaban - a safe therapeutic option in patients with antiphospholipid syndrome? Our experience in 23 cases. Reumatologia 2016;3:146-149.

8. Joalland F, de Boysson H, Darnige L, Johnson A, Jeanjean C, Cheze S, Augustin A, Auzary C, Geffray L. Seronegative antiphospholipid syndrome, catastrophic syndrome, new anticoagulants: learning from a difficult case report [article in French]. Rev Med Interne 2014;35:752-756.
9. Delgado MG, Rodríguez S, García R, Sánchez P, Sáiz A, Calleja S. Antiphospholipid Syndrome of Late Onset: A Difficult Diagnosis of a Recurrent Embolic Stroke. J Stroke Cerebrovasc Dis 2015;24:e209-e211.

10. Rokos J, Heger M, Stöllberger C, Finsterer J, Laufer G, Wiedemann D. Bipolar disorder, ischemic stroke, mitral valve vegetation and recurrent venous thrombosis due to antiphospholipid syndrome despite rivaroxaban. Int J Cardiol 2016;221:383-384.

11. Malec K, Góralczyk T, Undas A. The use of direct oral anticoagulants in 56 patients with antiphospholipid syndrome. Thromb Res 2017;152:93-97.

12. Erkan D, Aguiar CL, Andrade D, Cohen H, Cuadrado MJ, Danowski A, Levy RA, Ortel TL, Rahman A, Salmon JE, Tektonidou MG, Willis R, Lockshin MD. 14th International Congress on Antiphospholipid Antibodies: task force report on antiphospholipid syndrome treatment trends. Autoimmun Rev 2014;13:685-696.

13. Dufrost V, Risse J, Zuily S, Wahl D. Direct Oral Anticoagulants Use in Antiphospholipid Syndrome: Are These Drugs an Effective and Safe Alternative to Warfarin? A Systematic Review of the Literature. Curr Rheumatol Rep 2016;18:74.

14. Cohen H, Hunt BJ, Efthymiou M, Arachchillage DRJ, Mackie IJ, Clawson S, Sylvestre Y, Machin SJ, Bertolaccini ML, Ruiz-Castellano M, Muirhead N, Doré CJ, Khamashta M, Isenberg DA; RAPS trial investigators. Rivaroxaban versus warfarin to treat patients with thrombotic antiphospholipid syndrome, with or without systemic lupus erythematosus (RAPS): a randomised, controlled, open-label, phase 2/3, noninferiority trial. Lancet Haematol 2016;3:e426-e436.

15. Betancur JF, Bonilla-Abadia F, Hormaza AA, Jaramillo FJ, Canas CA, Tobon GJ. Direct oral anticoagulants in antiphospholipid syndrome: a real life case series. Lupus 2016;25:658-662.

16. Kunk P, Macik, B, Rice M. Non-Warfarin Oral Anticoagulants in Anti-Phospholipid Syndrome. Blood 2015;126:1133.

17. Sciascia S, Savino S, Breen K, Hunt BJ. Rivaroxaban use in patients with antiphospholipid syndrome and previous venous thromboembolism. Blood Coagul Fibrinolysis 2015;26:476477.

18. Pengo V, Banzato A, Bison E, Zoppellaro G, Padayattil Jose S, Denas G. Efficacy and safety of rivaroxaban vs warfarin in high-risk patients with antiphospholipid syndrome: Rationale and design of the Trial on Rivaroxaban in AntiPhospholipid Syndrome (TRAPS) trial. Lupus 2016;25:301-306.

\section{Author Affiliations}

Akanksha Joshi, MD; * Jason Hong, MD; + and

Chokkalingam Siva, MD, MS, FACP

*Division of Rheumatology, Department of Internal Medicine, University of Missouri, Columbia, Missouri, USA tDepartment of Medicine, University of Missouri, Columbia, Missouri, USA $¥$ Division of Rheumatology, Department of Internal Medicine, University of Missouri, Columbia, Missouri, USA 